\title{
Capillary disconnect during drying in model porous media at different wettability
}

\section{Rufai, A. K. ${ }^{\text {; }}$ Crawshaw, J. P. ${ }^{\mathrm{a}}$ *}

${ }^{\text {a }}$ Qatar Carbonates and Carbon Storage Research Centre, Department of Chemical Engineering, Imperial College London, London, UK. SW7 2AZ.

*E-mail of the corresponding author: j.crawshaw@imperial.ac.uk

\begin{abstract}
We carried out drying studies on a $2.5 \mathrm{D}$ micromodel based on a thin section of a carbonate rock to investigate the impact of wettability on the capillary disconnect, the moment when liquid films de-pin from the external evaporating surface. While this is coincident with the transition to low evaporation rate (diffusion limited) for deionized-water, our experiments show, the corner wetting films persisted after the transition to low evaporation rate for both water-wet and mixed-wet micromodels for brine, as solid salt continued to build up at the external evaporating surface. Fully oil wet micromodels showed a drying rate transition coincident with de-pinning.
\end{abstract}

Keywords: Capillary; Liquid films; Micromodel; Wettability; Crystallization. 


\section{Introduction}

Understanding the underlying physics of the drying process in contaminated porous media is central to many of its applications, such as soil remediation, gas injection into geological formations for enhanced oil recovery and $\mathrm{CO} 2$ sequestration processes, etc. Although many studies have been done on the kinetics of the drying process in porous media. There are still some knowledge gaps, especially when it comes to adequately predicting the extent of the different stages of evaporation in porous media of varying wettability. Classically, early stages of evaporation from a porous media are characterized by a relatively fast and "almost" constant evaporation rate, known as the constate rate period (CRP). This is followed by a transition period characterized by a large drop in evaporation rate, known as the falling rate period (FRP). The late stage of evaporation is characterized by a very slow evaporation rate limited by vapour diffusion through the porous media, this stage is known as the falling rate period (FRP)Materials and Methods [1-6].

The kinetics of the three periods are controlled by different mechanisms. For de-ionized water in a water-wet porous media, early stage evaporation is by water mass transfer by capillarity through wetting films to the evaporating surface, due to the stronger adhesion of water molecules to the pore walls compared to cohesive between water molecules [2]. Drying here is said to be controlled by external demand such as temperature, the flow rate of drying gas, relative humidity, the surface area of the evaporating surface and so on. During this period, the porous media behaves as though it is fully saturated because the mass transport through capillarity is sufficient to sustain evaporative demand at the surface $[3,5]$. Simply, the constant rate period is dominated by capillarity due to hydraulically connected pores [7]. In time, gravity and viscous forces will overcome the capillary driving forces at some depth down the porous media, hydraulic connectivity to the evaporating surface will cease at this point and the drying surface will move to within the porous medium. This marks the end of the constant rate period (stage- 1 evaporation) and the beginning of the falling rate and receding front periods (stage-2 evaporation) [4, 5, 7].

There is a very sharp drop in evaporation rate during the falling rate period and , this period can also be called a transition stage as evaporation quickly transitions from a capillarity dominated period to a diffusion dominated period with continued drop in evaporation rate $[1,5,8]$ until complete drying (i.e. from CRP to RFP). Hence, internal mass transfers such as vapour diffusion, pore space geometry, thermal and hydraulic conductivities etc. control drying during stage- 2 evaporation. Here, the drying rate varies linearly with the square root of time [5, 9]. The drying of brine-containing porous media such as saline aquifers, oil and gas reservoirs, building materials etc. causes the dissolved salt to crystallise within (subflorescence) and outside (efflorescence) the porous media when the solubility limit of the salt is exceeded [10]. Salt crystallization (crystallisation/dissolution cycles) can cause a 
lasting damage to building materials, and these problems are been studied extensively within the civil engineering research community [11-15]. Salt crystallisation can also lead to a significant decrease in porosity and permeability of underground reservoirs like saline aquifers. This decrease in permeability can lead to an increase in injection cost and a reduction of storage potential during $\mathrm{CO} 2$ sequestration processes.

A number of phenomena affect drying dynamics and the consequent salt deposition in a porous medium, some of these phenomena have been studied and reported in past literature. For example, the drying rate is strongly influenced by the spatial distribution of the liquid and that, in turn, is controlled by capillary forces at the pore scale. However, the effect of the wetting films and corner menisci on drying kinetics and salt crystallization is still somewhat unclear. In the present study, we aim to shed more light on the effect of porous media wetting conditions on the different stages of evaporative drying. Given that oil reservoirs have a wide range of contact angles (wetting states) and with the fact that capillarity through corner wetting films is strongly dependent on the wetting states of the pore walls. One can assume that the disconnection in capillarity or depinning of the wetting films from the evaporating surface (marking the end of stage-1 evaporation) will be strongly affected by the wetting state of the porous media. Lastly, we have carried out this study with a model porous media, a micromodel based on a thin section image of a carbonate rock. Working with micromodels allow us faster observations (better time resolutions) and direct visual observation of pore-scale processes in a network of pores.

\section{Materials and Methods}

This study was done using micromodels that are based on a thin-section image of a sucrosic dolomite rock [5, 9]. These micromodels were fabricated with a silicon wafer, covered with a transparent glass, allowing direct real-time visualization of pore-scale processes. The micromodel has a constant etch depth of $25 \mu \mathrm{m}$, with a matrix dimensions of $2.5 \mathrm{x} 1 \mathrm{~cm}^{2}$. A DSLR (digital single-lens reflex) camera (D800E, Nikon) and an inverted light microscope (AxioObserver A1.m, Zeiss) was used to obtain a wide field of view and high-resolution images respectively. Freshly prepared $\mathrm{NaCl}$ solutions were prepared for the different concentrations used in this study, i.e. $0 \mathrm{wt} \%$ (deionized water), $18 \mathrm{wt} \%$ (3M NaCl solution) and $36 \mathrm{wt} \% \mathrm{NaCl}$ solution (6M or saturated $\mathrm{NaCl}$ solution). Fluorescein (46960-2SG-F, Sigma-Aldrich. 1:700000 v/v) was added to the brine solutions for easier phase differentiation. Brine was injected with a $10 \mathrm{~mL}$ syringe (BD Plasipak, BD300013) using s programmable syringe pump (BS-80000, Braintree Scientific Ltd.). After saturating the micromodel with brine, dry air flow-line was attached to one of the inlet ports, while its adjacent port was opened to the atmosphere for continuous flow of dry air through one of the fracture channels in front of the matrix for evaporative drying. As the drying front moves back into the matrix, images of the dry-out evolution were taken at different time intervals and the salt precipitation in its wake was observed in real time. To obtain 
quantitative data from the images, ImageJ was used to calculate the dry pore area (equivalent to mass lost by evaporation) of each of the captured images. More explicit details on the micromodels, imaging techniques, experimental procedure and quantitative data acquisition are provided in two recently published papers [5, 9].

\subsection{Micromodel Wettability Alteration Technique}

The micromodels were originally water-wetting by oxidation of the silicon wafer at high temperature during the manufacturing process. To obtain, mixed-wet and oil-wet conditions, the micromodels were treated with a new wettability alteration technique. Well established techniques based on silane chemistry [16] could not be used because the silane reacts with the water phase (necessary to the generation of mixed wettability) during the treatment. Also, alteration with crude oil [17] could not be used because it renders the micromodel opaque after treatment. The new technique involves a solution of silicone caulk (151 Products Ltd.) (10v/v \%) dissolved in Dodecane ( $\geq 99 \%$, Sigma-Aldrich) (90v/v \%). For mixed-wetting conditions, this solution was injected into the micromodel initially saturated with deionized water and then left to age for about 2 days at ambient conditions. Note that this leaves water wet corners in channels that are otherwise altered to oil wet. The micromodel was then dried by passing dry compressed air through it, before placing it in an oven at $60^{\circ} \mathrm{C}$ for 24 hours. For uniformly oil-wetting conditions, the silicone solution was injected straight into a dry micromodel. More details of this new technique are provided in a recently published paper [9].

\section{Results and Discussion}

We determined the evaporation rates from the experiments by calculating the pore dry area as a function of time. The evaporation rates at ambient conditions and a relative humidity approximately equal to zero for $0 \mathrm{wt} \% \mathrm{NaCl}$ (deionised water), $18 \mathrm{wt} \% \mathrm{NaCl}$ brine and 36 wt\% $\mathrm{NaCl}$ (saturated brine) solution in a water-wet micromodel are plotted in figure $1 \mathrm{a}$. The evaporation rates were initially almost constant before a sharp drop after about 2mins for deionised water, $1 \mathrm{~min}$ for $18 \mathrm{wt} \% \mathrm{NaCl}$ and almost immediately for saturated $\mathrm{NaCl}$ brine. For deionised water these periods correspond to the classical periods of evaporation expected from earlier experiments and modelling in porous media drying: stage-1 evaporation (or the CRP) in which liquid remains connected to the drying surface through capillary forces, and the stage- 2 evaporation (a combination of the FRP and the RFP) at which the hydraulic capillary connection to the evaporating surface is broken and water transport becomes dominated by vapour diffusion.

From figure 1a, the same trend of two stages can be seen for the plots of $18 \mathrm{wt} \% \mathrm{NaCl}$ brine and saturated $\mathrm{NaCl}$ brine albeit with different duration for their stage- 1 evaporation. The stage- 1 evaporation is almost non-existent for the saturated $\mathrm{NaCl}$ brine. However, unlike the deionized case, the transition to stage-2 with brine is not due to capillary 
disconnect to the evaporating surface because we continue to see a gradual increase in the amount of salt deposited at the fracture channel, figure 2a and the salt can only be transported in the liquid phase.
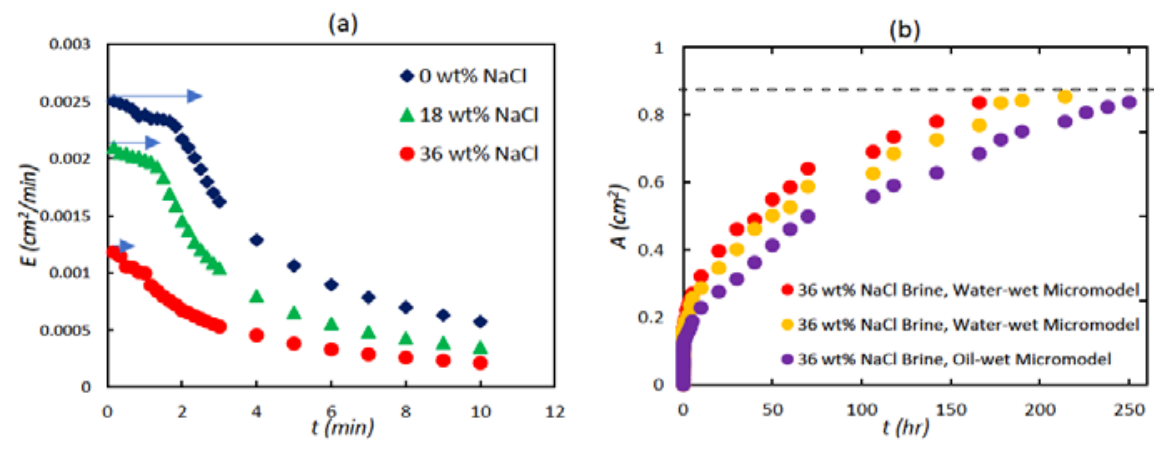

Figure 1. Evolution of drying: (a) Evaporation rate as a function of time for the water-wet micromodel (blue arrows signify the extent of the stage-1 evaporation) and (b) Dry pore area as a function of time for saturated $\mathrm{NaCl}$ brine at the three different wetting states ((horizontal black dotted line shows the total pore dry area $=0.7 \mathrm{~cm}^{2}$ ).

The change in slope for the brine solutions is due to the deposited solid salt acting as a physical to mass transfer to the surface, as well as the increase in the viscous resistance due to the relatively higher viscosity of the $\mathrm{NaCl}$ brine compared to deionized water.

The same evaporative drying procedure used for the water-wet micromodel was used for the mixed-wet and oil-wet micromodel. Figure $1 \mathrm{~b}$ shows the plot of the area of the micromodel occupied by air (equivalent to mass lost by evaporation) as a function of time for complete dry-out of saturated $\mathrm{NaCl}$ brine in the three wetting states. Although the trends in the plot of the three wetting states are very similar, the duration of complete dry-out increases systematically from the water-wet to oil-wet micromodel. This is as a result of the absence of corner wetting films needed for the high evaporation rate, especially during stage-1 evaporation. Less salt was deposited in the fracture channel of the mixed-wet micromodel compared to the water-wet micromodel as seen in the images in figure $2 \mathrm{~b}$.

(a)

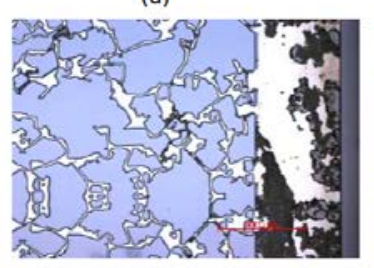

(b)

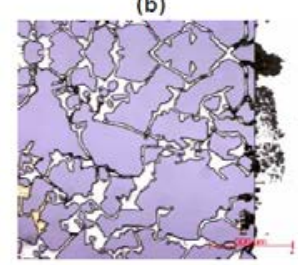

(c)

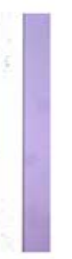

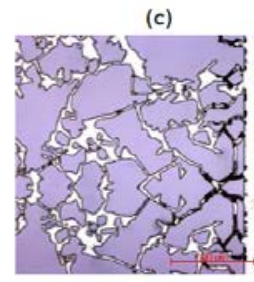

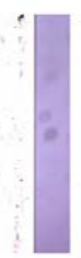

Figure 2. Images showing deposited salt in the evaporating surface and in the matrix below at the end of complete drying (i.e. liquid saturation =0) for (a) Water-wet micromodel, (b) Mixed-wet micromodel and (c) Oil-wet micromodel. 
Further, only a very small amount of salt (probably from the brine solution present in the channel prior to drying) were deposited at the evaporating surface for the oil-wet micromodel, figure 2c. The reason for this is the absence of wetting films needed to maintain hydraulic connectivity to the surface in the fully oil wet case.

Finally, results for the $36 \mathrm{wt} \% \mathrm{NaCl}$ brine in a water-wet micromodel and oil-wet micromodel are compared directly in figure 3 below. The schematics show liquid films at the corners of the micromodel grains percolating at the onset of drying. The thickness of the films decreases as drying continues until no connected pathway remains to the external evaporating surface. For deionized water, this would mark the onset of slower, stage-2, evaporation. However, from our experiment, the corner wetting films persisted after the transition to low evaporation rate, as sold salt continued to build up at the external evaporating surface.

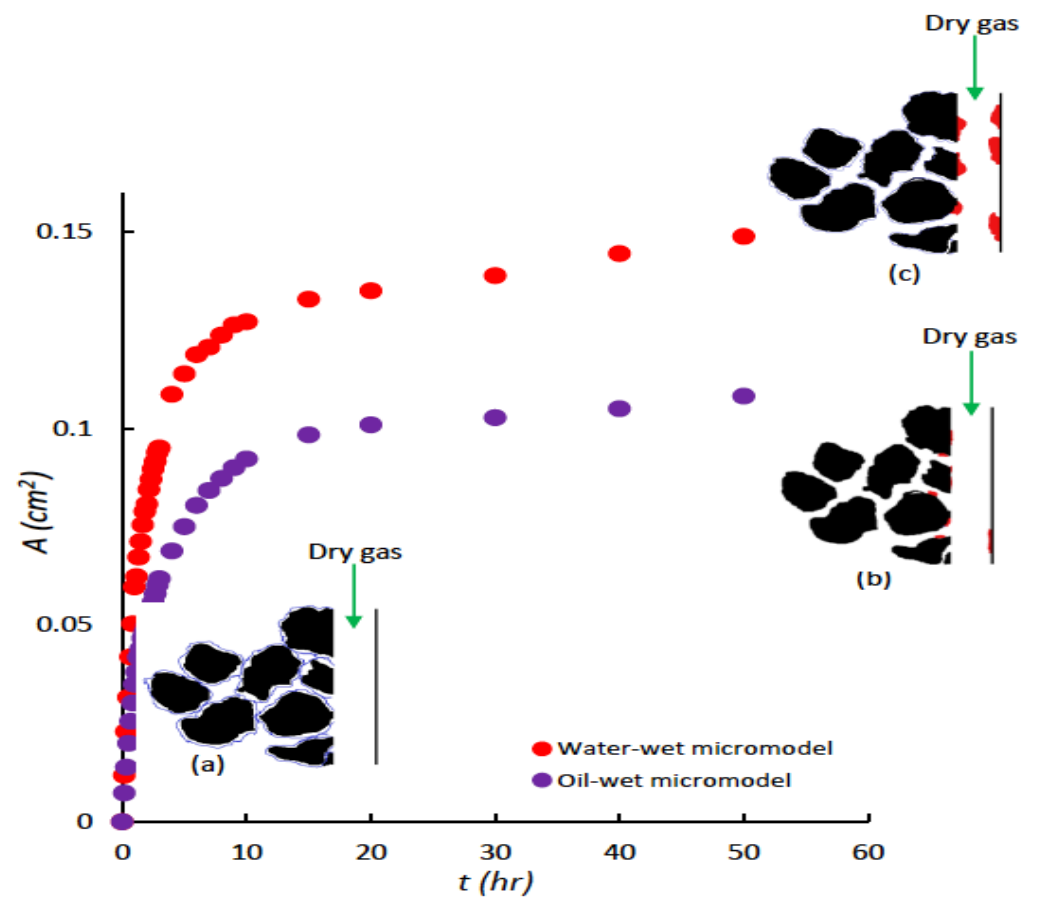

Figure 3. Dry pore area as a function of time for a $36 \mathrm{wt} \% \mathrm{NaCl}$ brine (saturated) solution in a water-wet micromodel and oil-wet micromodel. The inset images are schematic representations of a section of the micromodel (fracture and matrix) at different times. (a) At the onset of drying with

fracture full of gas and thick corner wetting films $(t \approx 10 \mathrm{~s})$. (b) During drying in an oil-wet micromodel, with little solid salt in fracture and no corner wetting films ( $t \approx 30 \mathrm{mins})$. (c) During drying in a water-wet micromodel, with solid salt in fracture and very thin corner wetting films $(t \approx$ 30mins). Model grains are represented in black, wetting films are indicated in light blue while deposited solid salt is represented in red. 


\section{Conclusions}

During the CRP (stage-1 evaporation), dry air entering the micromodel to balance the water loss becomes saturated with water vapour, leading to little evaporation occurring at this stage. We studied the effect of capillarity, wetting state and salt precipitation on the duration of the CRP from a model porous media. Evaporation from water-wet and mixedwet micromodels saturated with deionized water ( $0 \mathrm{wt} \%$ brine) were similar and follow the well-established theory of drying from a porous media: a constant, high evaporation rate maintained by capillary forces through wetting films to the evaporating surface, followed by a transition (break in capillarity to the evaporating surface) to a much lower evaporation rate (stage-2 evaporation) characterized by vapour diffusion. However, for the brine solutions (18 wt\% and $36 \mathrm{wt} \% \mathrm{NaCl}$ brine), capillarity to the evaporating surface was maintained even during stage-2 evaporation, evidenced by the continuous deposition of salt in the fracture of the micromodel well into the FRP (stage-2 evaporation). Hence, the capillary connection can be maintained even during the FRP for the drying of brine contaminated porous media.

The evaporation dynamics for a mixed-wet micromodel and a water-wet micromodel are very similar, the only difference is the slightly earlier transition observed in the mixed-wet micromodel. On the other hand, the oil-wet micromodel emphasized the effect of the wetting state on the evaporation dynamics. The evaporation rate dropped as soon as drying started as a result of the absence of corner wetting films needed to supply evaporative demand at the surface. This leads to very little deposited salt at the fracture as well as an increase in the overall drying time.

\section{Acknowledgements}

We gratefully acknowledge funding for this $\mathrm{PhD}$ research from the Petroleum Technology Development Fund, provided by the Nigerian Government. This work was done using equipment provided by the Qatar Carbonates and Carbon Storage Research Centre (QCCSRC). We gratefully acknowledge the funding of QCCSRC provided jointly by Qatar Petroleum, Shell, and the Qatar Science \& Technology Park.

\section{References}

[1] N. Shokri, P. Lehmann, and D. Or, "Characteristics of evaporation from partially wettable porous media," Water Resources Research, vol. 45, no. 2, p. W02415, 2009.

[2] F. Chauvet, P. Duru, S. Geoffroy, and M. Prat, "Three periods of drying of a single square capillary tube," Physical review letters, vol. 103, no. 12, p. 124502, 2009.

[3] G. W. Scherer, "Theory of drying," Journal of the American Ceramic Society, vol. 73, no. 1, pp. 3-14, 1990. 
[4] P. Lehmann, S. Assouline, and D. Or, "Characteristic lengths affecting evaporative drying of porous media," Physical Review E, vol. 77, no. 5, p. 056309, 2008.

[5] A. Rufai and J. Crawshaw, "Micromodel observations of evaporative drying and salt deposition in porous media," Physics of Fluids, vol. 29, no. 12, p. 126603, 2017.

[6] J. Van Brakel, "Mass transfer in convective drying," 1980.

[7] N. Shokri, P. Lehmann, and D. Or, "Critical evaluation of enhancement factors for vapor transport through unsaturated porous media," Water resources research, vol. 45, no. 10, 2009.

[8] N. Shokri, P. Lehmann, and D. Or, "Evaporation from layered porous media," Journal of Geophysical Research: Solid Earth, vol. 115, no. B6, 2010.

[9] A. Rufai and J. Crawshaw, "Effect of Wettability Changes on Evaporation Rate and the Permeability Impairment due to Salt Deposition," ACS Earth and Space Chemistry, vol. 2, no. 4, pp. 320-329, 2018.

[10] D. Le, H. Hoang, and J. Mahadevan, "Impact of capillary-driven liquid films on salt crystallization," Transport in porous media, vol. 80, no. 2, pp. 229-252, 2009.

[11] G. W. Scherer, "Crystallization in pores," Cement and Concrete Research, vol. 29, no. 8, pp. 1347-1358, 1999.

[12] A. Goudie and H. A. Viles, Salt weathering hazard. Wiley, 1997.

[13] G. W. Scherer, "Drying, shrinkage, and cracking of cementitious materials," Transport in Porous Media, vol. 110, no. 2, pp. 311-331, 2015.

[14] D. Everett, "The thermodynamics of frost damage to porous solids," Transactions of the Faraday Society, vol. 57, pp. 1541-1551, 1961.

[15] M. Steiger, "Crystal growth in porous materials-I: The crystallization pressure of large crystals," Journal of crystal growth, vol. 282, no. 3-4, pp. 455-469, 2005.

[16] J. W. Grate et al., "Silane modification of glass and silica surfaces to obtain equally oil-wet surfaces in glass-covered silicon micromodel applications," Water Resources Research, vol. 49, no. 8, pp. 4724-4729, 2013.

[17] A. S. Al-Menhali and S. Krevor, "Capillary Trapping of CO2 in Oil Reservoirs: Observations in a Mixed-Wet Carbonate Rock," Environmental Science \& Technology, vol. 50, no. 5, pp. 2727-2734, 2016/03/01 2016. 